\title{
Circuit-theory-based method for transmission fixed cost allocation based on game-theory rationalized sharing of mutual-terms
}

\author{
Saeid POUYAFAR ${ }^{1}$, Mehrdad TARAFDAR HAGH ${ }^{1,2}$ (i), \\ Kazem ZARE ${ }^{1}$
}

\begin{abstract}
This paper proposes a new method to allocate the transmission fixed costs among the network participants in a pool-based electricity market. The allocation process relies on the circuit laws, utilizes the modified impedance matrix and is performed in two individual steps for the generators and loads. To determine the partial branch power flows due to the participants, the equal sharing principle is used and validated by the Shapley and Aumann-Shapley values as two preferred game-theoretic solutions. The proposed approach is also applied to determine the generators' contributions into the loads, and a new concept, named circuit-theory-based equivalent bilateral exchange (EBE), is introduced. Using the proposed method, fairly stable tariffs are provided for the participants. Cross-subsidies are reduced and a fair competition is made by the proposed method due to the counter-flows being alleviated compared with the well-known Z-bus method. Numerical results are reported and discussed to validate the proposed cost allocation method. Comparative analysis reveals that the method satisfies all conditions
\end{abstract}

CrossCheck date: 25 September 2018

Received: 28 February 2018/Accepted: 26 September 2018/ Published online: 17 January 2019

(C) The Author(s) 2019

$\triangle$ Mehrdad TARAFDAR HAGH

tarafdar@tabrizu.ac.ir

Saeid POUYAFAR

s.pouyafar@tabrizu.ac.ir

Kazem ZARE

kazem.zare@tabrizu.ac.ir

1 Department of Electrical and Computer Engineering, University of Tabriz, Tabriz, Iran

2 Engineering Faculty, Near East University, Mersin 10, 99138 Nicosia, North Cyprus, Turkey desired in a fair and efficient cost allocation method. Finally, the developed technique has been implemented successfully on the 2383-bus Polish power system to emphasize that the method is applicable to very large systems.

Keywords Transmission fixed cost allocation, Circuit theory, Equal sharing principle, Game theory

\section{Introduction}

Among various issues related to the modern restructured power systems well addressed most recently in the literature $[1,2]$, deregulation and its price-based problems [3, 4] are of utmost importance. One of these problems is transmission cost allocation (TCA). Several methodologies have been proposed in the literature concerning the problem of TCA. Traditionally, the costs were allocated to the users by the Pro-Rata method. Despite the simplicity, the method disregards the network actual extent of use. Recently, the method is enriched and used to allocate the costs of the unused capacity of the transmission facilities. The task of allocating the transmission costs to the users taking into account the network extent of use, was first introduced by the MW-mile method which is now widely applied in the literature [5].

Tracing-based methods [6-8] utilize the concept of proportional sharing principle (PSP) to trace the power flow in the network. Reference [6] proved the existence and uniqueness of a solution to the tracing problem. The technique of flow tracing has also been extended and used as an analytical tool for transmission capacity allocation in a highly renewable European electricity system [7]. Reference [8] presented a transmission congestion (TC) 
tracing technique based on PSP. Nodal pricing is another approach for TCA which is based on locational marginal price (LMP) differences, and is currently developed worldwide. The proposed marginal pricing approach provides the correct economic signals to the network participants. However, it is not linked to the actual transmission infrastructure cost, thus, not able to recover the total transmission network cost (TNC) [9]. Reference [10] checked this fact in several systems around the world utilizing LMP-based TCA method, and demonstrated that the maximum network revenue obtained in these systems was only $25 \%$ of the TNC. Some authors tried to solve the issue by altering the LMPs to recover the TNC using the concept of Ramsey pricing [10], and introducing the generation and nodal injection penalties into the economic dispatch [11]. Marginal and incremental cost allocation methods, based on the concept of sensitivity indices, are other pricing schemes widely applied in the literature, until recently [12]. The main drawback of these methods is their sensitivity to the choice of the slack bus. To overcome this limitation, [5] utilized the slack bus independent distribution factors, whereas [13] suggested the concept of optimal distributed slack bus. TCA methods based on some form of equivalents have been extended in $[14,15]$, in which the equivalent bilateral exchange (EBE) has been built through the optimization as well as tracing-based approaches, respectively. As an alternative, the optimization approach has been used recently along with the min-max fairness criteria [16] to trace the real power in the network. The application of artificial intelligence (AI) to power system becomes popular to explore, especially in power tracing problems [17]. Effect of the possible interactions of components is often not considered in neither optimization nor AI-based methods, due to its additive complexity as well as the computation time, subsequently leading to inaccuracy in some cases.

There are also a group of papers, with solid economical foundation, that incorporate the concept of cooperative game theory $[18,19]$ into the problem of TCA. Although the method behaves well in terms of fairness and efficiency, significantly high computation time is required, if applied to a large power system [20]. Recently, [21] proposed a benefit-based TCA scheme. The challenging issue concerning these methods is to find the exact benefit that each user takes from the transmission facilities. Reference [22] introduced a new load-following-based method to estimate the transmission costs of each participant during a specified time period before entering the market.

The use of circuit theory to the TCA is another pricing scheme, widely applied in the literature [19, 23-28]. The circuit-theory-based approaches, including Z-bus model $[23,24]$ as well as its modified forms [26, 28], modified nodal equation (MNE) model [25], and transformer analogy (TA) model [27], have an important advantage over any cost allocation method, as previously described. These methods incorporate the network characteristics directly into the allocation process. However, due to the non-linear behavior of the power systems, there is still not a unique mathematical solution for the contribution of customers into the transmission facilities under these approaches. The results rely mostly on the principle applied to split the mutual terms, as the main causes of the nonlinearity, between the participants. A group of papers use the most common sharing principles, namely, proportional [29], quadratic [30], and equal sharing [19, 28, 31] to split the mutual terms, whereas the others [23-27] avoid the mutual terms by considering a single variable at a time. In [29], it is revealed that proportional and equal sharing principles bring about more reasonable results for reactive power allocation, compared with the single variable division.

Based on the arguments, this paper presents a new circuit-theory-based TCA method which is developed based on the modified Z-bus model. The proposed technique applies the equal-sharing principle to split the mutualterms, and subsequently to determine the partial branch power flows due to the participants. It also uses the Shapley as well as the Aumann-Shapley values, as two preferred cooperative game solution concepts to validate the sharing principle applied. Moreover, a new concept, named circuittheory-based EBE, is introduced by determining the generators and loads contributions into each other.

The innovative contributions of the paper are:

1) The proposed method is applicable to very large systems, since it requires less computational efforts, and overcomes the limitations of the existing Z-bus and proportional sharing (PS) methods to invert the large-scale sparse matrices.

2) The proposed cost allocation method is fair and efficient and is more likely to be accepted by the participants, because it is confirmed by the game theoretic solutions, and also reflects the order of magnitude of generators and loads as well as their locations in the grid.

3) The proposed method smooths the trend of the Z-bus method to reflect the counter-flows, and, in turn, helps to reduce the cross-subsidies. This property is truly valuable, as higher counter-flows with excessive rewards result in unfair competition, and make the results change significantly when different MW-mile pricing schemes are used.

4) Highest tariff stability against temporal variations are observed by the proposed method, compared with the Z-bus and PS methods. 
5) The proposed method is less sensitive to the calculation reference side of the lines, compared with the Z-bus method.

6) The proposed method works consistently for all network configurations, as it overcomes the singularity problems of the similar methods to build the impedance matrix.

\section{Modified Z-bus theory}

In this study, due to page limit, only the contributions of the generators are considered. Therefore, the generators are treated as current injections and the loads as equivalent impedances.

For a power system with $N_{\mathrm{b}}$ buses and $N_{\mathrm{l}}$ lines, suppose that there are $N_{\mathrm{g}}$ generator buses and $N_{\mathrm{d}}$ demand buses. Once the solution of a converged power flow or state estimator is obtained, system equivalent injection currents and admittance values will be as follows [23]:

$I_{n_{\mathrm{g}}}=\frac{P_{n_{\mathrm{g}}}-\mathrm{j} Q_{n_{\mathrm{g}}}}{V_{n_{\mathrm{g}}}^{*}}$

where $P_{n_{\mathrm{g}}}$ and $Q_{n_{\mathrm{g}}}$ are the power injected at the generator bus $n_{\mathrm{g}} ; V_{n_{\mathrm{g}}}$ is the voltage of the generator bus $n_{\mathrm{g}}$.

Likewise, the equivalent admittance for a load bus is:

$y_{n_{\mathrm{d}}}=\frac{P_{n_{\mathrm{d}}}-\mathrm{j} Q_{n_{\mathrm{d}}}}{\left|V_{n_{\mathrm{d}}}\right|^{2}}$

where $P_{n_{\mathrm{d}}}$ and $Q_{n_{\mathrm{d}}}$ are the power consumed at the demand bus $n_{\mathrm{d}} ; V_{n_{\mathrm{d}}}$ is the voltage of the demand bus $n_{\mathrm{d}}$.

Equivalent admittances of the loads are integrated into the network admittance matrix and the "network Y-mod matrix" is built.

Note that treating the loads as constant impedances rather than current injections and, in turn, integrating the load impedances into the network Y-bus matrix, in most cases, avoids the singularity problems concerning the impedance matrix building process. Note also that due to the TCA methods being developed based on the solved power flow of the system, and considering the fact that for power system steady-state studies, the actual modeling of the network loads does not influence the effectiveness of the results [32], among numerous static load models, the constant power PQ load model as the most appropriate one is considered in the proposed TCA method.

Using the network modified impedance matrix, $\boldsymbol{Z}_{\text {mod, }}$, to write the relationship between the bus voltages and the bus current injections, voltage of a given bus $k$ is expressed as:
$V_{k}=\sum_{n=1}^{N_{\mathrm{g}}} z_{k, n_{\mathrm{g}}} I_{n_{\mathrm{g}}}$

where $z_{k, n_{\mathrm{g}}}$ is the element of the $k^{\text {th }}$ row of the matrix $\boldsymbol{Z}_{\text {mod }}$. According to (3), contribution of the generator at bus $n_{\mathrm{g}}$ into the voltage of the bus $k$ is:

$V_{k, n_{\mathrm{g}}}=z_{k, n_{\mathrm{g}}} I_{n_{\mathrm{g}}}$

If bus $k$ is a demand bus, its complex power consumption can be written as:

$S_{k}=V_{k} i_{k}^{*}=y_{k}^{*} V_{k} V_{k}^{*}$

Applying (3) into (5), we have:

$S_{k}=y_{k}^{*}\left(\sum_{n_{\mathrm{g}}=1}^{N_{\mathrm{g}}} z_{k, n_{\mathrm{g}}} I_{n_{\mathrm{g}}}\right)\left(\sum_{n_{\mathrm{g}}=1}^{N_{\mathrm{g}}} z_{k, n_{\mathrm{g}}}^{*} I_{n_{\mathrm{g}}}^{*}\right)$

Similarly, for a given line $a b$, its complex power flow can be written as follows:

$S_{a b}=V_{a} I_{a b}^{*}=V_{a}\left[y_{a b}^{*}\left(V_{a}^{*}-V_{b}^{*}\right)+\frac{1}{2} y_{a, \mathrm{sh}} V_{a}^{*}\right]$

where $S_{a b}$ and $I_{a b}$ are the power and current flow; $y_{a b}$ and $y_{a, \mathrm{sh}}$ are series and shunt admittances of the line $a b$, respectively. Substituting equivalent values of the bus voltages from (3) into (7), we have:

$$
\begin{aligned}
S_{a b}= & \left(\sum_{n_{\mathrm{g}}=1}^{N_{\mathrm{g}}} z_{a, n_{\mathrm{g}}} I_{n_{\mathrm{g}}}\right) \\
& \times\left[y_{a b}^{*} \sum_{n_{\mathrm{g}}=1}^{N_{\mathrm{g}}}\left(z_{a, n_{\mathrm{g}}}^{*}-z_{b, n_{\mathrm{g}}}^{*}\right) I_{n_{\mathrm{g}}}^{*}+\frac{1}{2} y_{a, \mathrm{sh}} \sum_{n_{\mathrm{g}}=1}^{N_{\mathrm{g}}} z_{a, n_{\mathrm{g}}}^{*} I_{n_{\mathrm{g}}}^{*}\right]
\end{aligned}
$$

\section{Sharing principles of mutual-terms}

As seen in (6) and (8), the network power equations are made up of self-terms, that is, the contribution of an individual component, and mutual-terms, given by the product of two distinct components. Thereby, it is necessary to split the mutual terms, to allocate the power equations between the involved components.

In general, a simple form of the problem of dividing a mutual term between two involved components can be expressed as follows:

$\left\{\begin{array}{l}f\left(x_{i}, x_{j}\right)=2 x_{i} x_{j}=\alpha_{i} x_{i} x_{j}+\alpha_{j} x_{i} x_{j} \\ \text { s.t. } \alpha_{i}+\alpha_{j}=2\end{array}\right.$

where $x_{i}$ and $x_{j}$ are the involved components of the mutualterm; $\alpha_{i}$ and $\alpha_{j}$ are the contribution coefficients of the components into the mutual-term, respectively. Mutualterms are divided between the involved components, based 
on the criteria applied to calculate the contribution coefficients of the components. Commonly used sharing principles of mutual-terms are proportional, quadratic, and equal or 50-50 sharing.

Proportional sharing principle assumes that the coefficients $\alpha_{i}, \alpha_{j}$ are directly proportional to their relevant components:

$\frac{\alpha_{i}}{x_{i}}=\frac{\alpha_{j}}{x_{j}}$

Regarding the constraint of (9) we have:

$\left\{\begin{array}{l}\alpha_{i}=\frac{2 x_{i}}{x_{i}+x_{j}} \\ \alpha_{j}=\frac{2 x_{j}}{x_{i}+x_{j}}\end{array}\right.$

Based on the quadratic sharing principle, however, the coefficients $\alpha_{i}, \alpha_{j}$, are proportional to the square of their relevant components:

$\frac{\alpha_{i}}{x_{i}^{2}}=\frac{\alpha_{j}}{x_{j}^{2}}$

Again, regarding the constraint of (9) we have:

$\left\{\begin{array}{l}\alpha_{i}=\frac{2 x_{i}^{2}}{x_{i}^{2}+x_{j}^{2}} \\ \alpha_{j}=\frac{2 x_{j}^{2}}{x_{i}^{2}+x_{j}^{2}}\end{array}\right.$

Equal sharing model, on the other hand, assumes an equal and unitary value for the coefficients $\alpha_{i}, \alpha_{j}$ :

$\alpha_{i}=\alpha_{j}=1$

The sharing principles cannot be proved mathematically, however, if any of them is confirmed by a game-theoretic solution belonging to the core of the game, which is more likely to bring about sensible results.

\section{Game-theoretic solutions}

If a solution belongs to the core of the game, it is more likely to be accepted by the participants, because the problem of cross-subsidy is avoided. However, based on the game played, the core may consist of more than one point or it may be empty.

To allocate the transmission costs among the users based on the game theory, a cost game has to be defined first, given by the pair $(N, c)$, where $N=\{1,2, \ldots, n\}$ is the set of players and $c$ is a function that assigns a real number to each subgroup (coalition) of $N$. A solution to the cost game is a cost allocation, i.e., a vector $\boldsymbol{x} \in \mathbf{R}^{n}$, where any element $x_{i}$ of vector $\boldsymbol{x}$ is the cost allocated to player $i$. The solution is called to be in the core, if, the following rationality requirements hold:

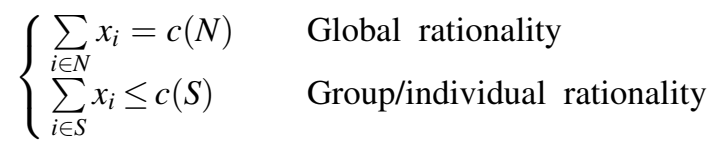

where $\forall S \subseteq N$.

The Shapley value is a single point solution to the cost game, which is defined as follows. For a $n$-player coalitional game with real-valued gain function $v(\cdot)$, a unique imputation of the total gain to each player $i$, denoted by $\phi_{i}$ $(i=1,2, \ldots, n)$, is given by the Shapley value:

$\phi_{i}=\sum_{S^{-i} \subseteq N \backslash\{i\}} \frac{S^{-i} \mid !\left(n-\left|S^{-i}\right|-1\right) !}{n !}\left[v\left(S^{-i} \cup\{i\}\right)-v\left(S^{-i}\right)\right]$

where $S^{-i}$ is an arbitrary subset of $N$ with the $i^{\text {th }}$ player always excluded (denoted by $\backslash\{i\}$ ); $S^{-i} \mid$ is the number of players in subset $S^{-i}$. According to (16), the coalitional rationality of (15) is not a requirement, so the Shapley value does not always belong to the core. However, under the whole network game, in most cases, the coalitional rationality holds for the Shapley value solution, thus, it belongs to the core as well. In the context of the Shapley value being a part of the core, it is more preferable than other single point solutions, as it holds the axioms of symmetry, efficiency, additivity, and dummy player [33].

There exists another single point solution, namely, the Aumann-Shapley, which is a natural consequence of the Shapley value method. It is based on the premise that each agent has to be sub-divided into infinitesimal sub-agents, and the Shapley method is applied to each one as if each sub-agent were an individual [19].

Despite the fact that the game-theoretic solutions result in fair and efficient results, they are not a common TCA method, because these solutions on realistic sized problems require too much input data, which makes the handling of the game dimension a challenging issue. For example, the calculations for a network with $n$ participants require $2^{n}-1$ pieces of input data [20]. However, the game-theoretical solutions may be used as a framework to evaluate the results of any other usage-based methods, or to prove whether a mathematical model is rational.

\section{Proposed method}

In this section, first, we use the Shapley as well as the Aumann-Shapley values, as two preferred cost game solutions, to confirm the equal sharing principle. Then, we apply the equal sharing principle to determine the branch power flow contributions of the participants. The results are then used to allocate the network costs among the users. 


\subsection{Validating the equal sharing principle}

We apply the Shapley value to solve the general mutual term division problem, defined by (9).

The problem to be studied might be described as follows: how to impute $2 x_{i} x_{j}$ to each of $x_{i}$, and $x_{j}$. We first compute the gains $v(\cdot)$, i.e., the value of $2 x_{i} x_{j}$ when two sources each acts alone and act together.

$$
\left\{\begin{array}{l}
v(\{i\})=2 x_{i} \times 0=0 \\
v(\{j\})=0 \\
v(\{i, j\})=2 x_{i} x_{j}
\end{array}\right.
$$

Using the detailed form of the Shapley value formula (16), the imputation component of $f\left(x_{i}, x_{j}\right)$ to source $x_{i}$, denoted by $f^{x_{i}}$, is:

$$
\begin{aligned}
f^{x_{i}}= & \frac{0 !(2-0-1) !}{2}[v(\{i\})-0] \\
& +\frac{1 !(2-1-1) !}{2}[v(\{i, j\})-v(\{j\})] \\
= & \frac{1}{2} 2 x_{i} x_{j}=x_{i} x_{j}
\end{aligned}
$$

Similarly, the imputation component of $f\left(x_{i}, x_{j}\right)$ to source $x_{j}$ is calculated. The results, confirms the equal sharing of mutual terms, as the shares of $x_{i}$ and $x_{j}$ on $2 x_{i} x_{j}$, are the same and each equals $x_{i} x_{j}$.

We perform the same procedure by the Aumann-Shapley value to split the mutual term, $f\left(x_{i}, x_{j}\right)$, between its involved components, $x_{i}, x_{j}$. Based on the Aumann-Shapley value solution concept, unitary participation (UP) of $x_{i}$ into the $f\left(x_{i}, x_{j}\right)$ is:

$U P_{\left(x_{i} \rightarrow f\right)}=\int_{t=0}^{1} \frac{\partial f(t x)}{\partial x_{i}} \mathrm{~d} t=\int_{t=0}^{1} 2\left(t x_{j}\right) \mathrm{d} t=\left.t^{2} x_{j}\right|_{0} ^{1}=x_{j}$

where each agent is divided into infinitesimal parts $(\Delta x \rightarrow 0)$ by infinitesimal steps, $t$.

Likewise, solving the problem for UP of $x_{j}$ into the $f\left(x_{i}\right.$, $x_{j}$ ), we obtain:

$U P_{\left(x_{j} \rightarrow f\right)}=\int_{t=0}^{1} \frac{\partial f(t x)}{\partial x_{j}} \mathrm{~d} t=\int_{t=0}^{1} 2\left(t x_{i}\right) \mathrm{d} t=\left.t^{2} x_{i}\right|_{0} ^{1}=x_{i}$

To determine the total participation (TP) of the player into the $f\left(x_{i}, x_{j}\right)$, the unitary participation is multiplied by the amount of the player:

$\left\{\begin{array}{l}T P_{\left(x_{i} \rightarrow f\right)}=U P_{\left(x_{i} \rightarrow f\right)} \times x_{i}=x_{j} x_{i} \\ T P_{\left(x_{j} \rightarrow f\right)}=U P_{\left(x_{j} \rightarrow f\right)} \times x_{j}=x_{i} x_{j}\end{array}\right.$

It can be observed that the outcomes confirm the equal sharing of mutual terms.

\subsection{Allocating demand power of buses}

Applying the equal sharing model to spilt the mutual terms of the demand power expression (6) between the current injections, the contribution of the generator at bus $n_{\mathrm{g}}$ into the demand power at bus $k$ will be:

$S_{k, n_{\mathrm{g}}}=\frac{1}{2} y_{k}^{*}\left[z_{k, n_{\mathrm{g}}} I_{n_{\mathrm{g}}}\left(\sum_{n_{\mathrm{g}}=1}^{N_{\mathrm{g}}} z_{k, n_{\mathrm{g}}}^{*} I_{n_{\mathrm{g}}}^{*}\right)+z_{k, n_{\mathrm{g}}}^{*} I_{n_{\mathrm{g}}}^{*}\left(\sum_{n_{\mathrm{g}}=1}^{N_{\mathrm{g}}} z_{k, n_{\mathrm{g}}} I_{n_{\mathrm{g}}}\right)\right]$

Substituting (3) and (4) into (22), the simplified form of $S_{k, n_{\mathrm{g}}}$ will be:

$S_{k, n_{\mathrm{g}}}=\frac{1}{2} y_{k}^{*}\left(V_{k, n_{\mathrm{g}}} V_{k}^{*}+V_{k, n_{\mathrm{g}}}^{*} V_{k}\right)$

The expression obtained, may be applied to build the proposed circuit-theory-based EBE. The concept requires further investigation and will be developed in the future studies.

\subsection{Allocating power flow of branches}

Again, we use the equal sharing principle to split the mutual-terms of the branch power flow expressions between the current injections. Subsequently, the contribution of the generator at bus $n_{\mathrm{g}}$ into the power flow of the branch $a b$ will be:

$$
\begin{aligned}
S_{a b, n_{\mathrm{g}}}= & \frac{1}{2} y_{a b}^{*}\left\{z_{a, n_{\mathrm{g}}} I_{n_{\mathrm{g}}}\left[\sum_{n_{\mathrm{g}}=1}^{N_{\mathrm{g}}}\left(z_{a, n_{\mathrm{g}}}^{*}-z_{b, n_{\mathrm{g}}}^{*}\right) I_{n_{\mathrm{g}}}^{*}\right]\right. \\
& +\left(z_{a, n_{\mathrm{g}}}^{*}-z_{b, n_{\mathrm{g}}}^{*} I_{n_{\mathrm{g}}}^{*}\left(\sum_{n_{\mathrm{g}}=1}^{N_{\mathrm{g}}} z_{a, n_{\mathrm{g}}} I_{n_{\mathrm{g}}}\right)\right\} \\
& +\frac{1}{4} y_{a, \mathrm{sh}}^{*}\left[z_{a, n_{\mathrm{g}}} I_{n_{\mathrm{g}}}\left(\sum_{n_{\mathrm{g}}=1}^{N_{\mathrm{g}}} z_{a, n_{\mathrm{g}}}^{*} I_{n_{\mathrm{g}}}^{*}\right)+z_{a, n_{\mathrm{g}}}^{*} I_{n_{\mathrm{g}}}^{*}\left(\sum_{n_{\mathrm{g}}=1}^{N_{\mathrm{g}}} z_{a, n_{\mathrm{g}}} I_{n_{\mathrm{g}}}\right)\right]
\end{aligned}
$$

Using (3) and (4) to replace the related terms in (24), we have:

$$
\begin{aligned}
S_{a b, n_{\mathrm{g}}}= & \frac{1}{2} y_{a b}^{*}\left[V_{a b, n_{\mathrm{g}}}\left(V_{a}^{*}-V_{b}^{*}\right)+V_{a}\left(V_{a, n_{\mathrm{g}}}^{*}-V_{b, n_{\mathrm{g}}}^{*}\right)\right] \\
& +\frac{1}{4} y_{a, \mathrm{sh}}\left(V_{a, n_{\mathrm{g}}} V_{a}^{*}+V_{a, n_{\mathrm{g}}}^{*} V_{a}\right)
\end{aligned}
$$

\section{Numerical results}

In this section, the proposed method is compared with two well-known TCA techniques, namely, Z-bus theory [24], and PS method [6]. Two test systems namely 6-bus 
test system and IEEE 30-bus system are used. In the context of the 6-bus test system, a shortened time series study is performed to gain more insights into the behavior of the three TCA methods considered. In practice, a large number of time steps need to be analyzed for consecutive studies of large systems. However, the cyclical nature of load and generation profiles suggests that some time steps in the profiles represent load and generation scenarios that reappear over time, and hence can be simulated only once. In this respect, four time steps are considered in our study, which sufficiently represent the system off-peak, transitional, normal, and peak conditions. For the IEEE 30-bus system, system peak condition is considered. Any line tariff in $\$ / \mathrm{h}$, is set to be 1000 times its series reactance. Zero counter flow (ZCF) MW-mile pricing is used to charge the participants. Thus, the generators neither pay money nor take any reward for the lines in which their associated power flow is in opposite direction. Finally, the proposed method is applied to a practical system, namely, 2383-bus Polish 400, 220 and $110 \mathrm{kV}$ networks during winter 1999-2000 peak conditions, to emphasize the applicability of the method to very large systems. To know which type of electricity market with its regulations best suits a certain TCA technique, please refer to [34-36] which provide key information about transmission pricing experiences across various international jurisdictions.

\subsection{6-bus test system}

The 6-bus system as shown in Fig. 1 is considered. The displayed values on Fig. 1, represent the active power flows corresponding to the system peak condition. The system has eleven branches with parameters provided in Table 1, in which $r, x$, and $y$ denote the resistance, reactance, and shunt admittance of the branches, respectively. The time series study is performed for the three TCA methods, and the results are depicted in Tables 2, 3, 4, 5 and 6 . Table 2 represents the active power of the loads, generators and losses corresponding to the system four time steps considered. In Table 2, * signifies the minimum output capacity constraint of G1.

According to Tables 3, 4, 5 and 6, preliminary Kirchhoff's circuit laws are satisfied under the proposed as well as the Z-bus methods.

For each branch of the system, in each of the four time steps, the overall contribution due to the generators equals the power flow of the branch, under the proposed as well as PS methods. This is because, unlike Z-bus method, the proposed and PS methodologies perform the allocation process for the generators and loads, independently. Nevertheless, the partial branch power flows allocated to the users differ for these two methods. Discrepancies arise mainly due to the different underlying principles applied.

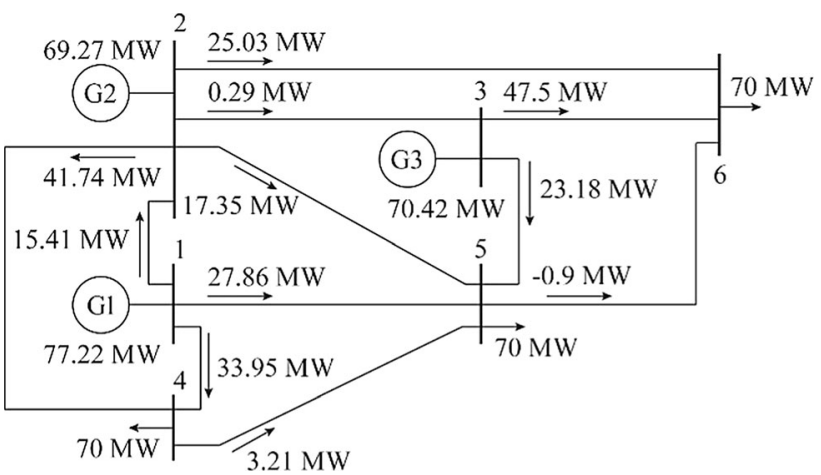

Fig. 1 6-bus test system

Table 1 6-bus test system branch data

\begin{tabular}{llll}
\hline Line & $r$ (p.u.) & $x$ (p.u.) & $y / 2$ (p.u.) \\
\hline $1-2$ & 0.10 & 0.20 & 0.02 \\
$1-4$ & 0.05 & 0.20 & 0.02 \\
$1-5$ & 0.08 & 0.30 & 0.03 \\
$2-3$ & 0.05 & 0.25 & 0.03 \\
$2-4$ & 0.05 & 0.10 & 0.01 \\
$2-5$ & 0.10 & 0.30 & 0.02 \\
$2-6$ & 0.07 & 0.20 & 0.02 \\
$3-5$ & 0.12 & 0.26 & 0.02 \\
$3-6$ & 0.02 & 0.10 & 0.01 \\
$4-5$ & 0.20 & 0.40 & 0.04 \\
$5-6$ & 0.10 & 0.30 & 0.03 \\
\hline
\end{tabular}

Table 2 Active power of loads, generators and losses corresponding to system four time steps

\begin{tabular}{lrrrrrrl}
\hline $\begin{array}{l}\text { Time } \\
\text { step }\end{array}$ & $\begin{array}{l}P_{\text {loss }} \\
(\mathrm{MW})\end{array}$ & $\begin{array}{l}P_{\mathrm{L} 4} \\
(\mathrm{MW})\end{array}$ & $\begin{array}{l}P_{\mathrm{L} 5} \\
(\mathrm{MW})\end{array}$ & $\begin{array}{l}P_{\mathrm{L} 6} \\
(\mathrm{MW})\end{array}$ & $\begin{array}{l}\mathrm{G} 1 \\
(\mathrm{MW})\end{array}$ & $\begin{array}{l}\mathrm{G} 2 \\
(\mathrm{MW})\end{array}$ & $\begin{array}{l}\mathrm{G} 3 \\
(\mathrm{MW})\end{array}$ \\
\hline 1 & 2.56 & 3.39 & 4.74 & 6.91 & $50.00^{*}$ & 42.56 & $45.00^{*}$ \\
2 & 45.00 & 45.00 & 60.00 & 70.00 & $50.00^{*}$ & 58.33 & $45.06^{*}$ \\
3 & 45.00 & 60.00 & 60.00 & 70.00 & $50.00^{*}$ & 74.37 & 60.37 \\
4 & 45.00 & 45.00 & 60.00 & 70.00 & 77.22 & 69.27 & 70.42 \\
\hline
\end{tabular}

PS method traces the power flows using the PSP which can be neither proved nor disproved, whereas the proposed method is based on the circuit theory and utilizes the network impedance matrix to determine the partial branch power flows due to the participants. In the case of the Z-bus method, however, the generators and loads are both treated as nodal currents, and hence, their responsibilities for network usage are calculated altogether in a common process.

Although the amounts of the contributions differ under the three methods, the dominant positive ones are the same for all the three methods, and belong to the generator(s) relatively close to the sending-end bus of the 
Table 3 Time series study of three TCA methods on 6-bus test system (time step 1)

\begin{tabular}{|c|c|c|c|c|c|}
\hline \multirow[t]{2}{*}{ Line number } & \multirow{2}{*}{$\begin{array}{l}\text { TCA } \\
\text { method }\end{array}$} & \multicolumn{4}{|c|}{ Power flow contribution (MW) } \\
\hline & & $P_{\text {line }}$ & G1 & G2 & G3 \\
\hline \multirow[t]{3}{*}{$1-2$} & Proposed & 9.96 & 10.46 & -1.03 & 0.54 \\
\hline & Z-bus & & 17.95 & -4.44 & -1.53 \\
\hline & PS & & 9.96 & 0.00 & 0.00 \\
\hline \multirow[t]{3}{*}{$1-4$} & Proposed & 22.02 & 11.76 & 4.16 & 6.09 \\
\hline & Z-bus & & 16.19 & 0.20 & 1.06 \\
\hline & PS & & 22.02 & 0.00 & 0.00 \\
\hline \multirow[t]{3}{*}{$1-5$} & Proposed & 18.02 & 9.85 & 4.41 & 3.76 \\
\hline & Z-bus & & 15.86 & 4.24 & 0.47 \\
\hline & PS & & 18.02 & 0.00 & 0.00 \\
\hline \multirow[t]{3}{*}{$2-3$} & Proposed & 0.25 & 2.89 & 3.11 & -5.75 \\
\hline & Z-bus & & 7.12 & 8.13 & -8.11 \\
\hline & PS & & 0.05 & 0.21 & 0.00 \\
\hline \multirow[t]{3}{*}{$2-4$} & Proposed & 25.73 & 3.04 & 11.07 & 11.62 \\
\hline & Z-bus & & -4.16 & 10.07 & 5.99 \\
\hline & PS & & 4.89 & 20.90 & 0.00 \\
\hline \multirow[t]{3}{*}{$2-5$} & Proposed & 10.82 & 2.69 & 5.06 & 3.06 \\
\hline & Z-bus & & 3.75 & 7.45 & 1.40 \\
\hline & PS & & 2.06 & 8.78 & 0.00 \\
\hline \multirow[t]{3}{*}{$2-6$} & Proposed & 15.61 & 6.28 & 7.45 & 1.89 \\
\hline & Z-bus & & 7.46 & 9.15 & -4.25 \\
\hline & PS & & 2.97 & 12.68 & 0.00 \\
\hline \multirow[t]{3}{*}{$3-5$} & Proposed & 14.73 & 0.87 & 3.13 & 10.73 \\
\hline & Z-bus & & 0.60 & 3.19 & 14.56 \\
\hline & PS & & 0.02 & 0.07 & 14.66 \\
\hline \multirow[t]{3}{*}{$3-6$} & Proposed & 30.49 & 5.09 & 6.36 & 19.05 \\
\hline & Z-bus & & 0.72 & 0.13 & 16.97 \\
\hline & PS & & 0.03 & 0.14 & 30.34 \\
\hline \multirow[t]{3}{*}{$4-5$} & Proposed & 1.86 & 1.30 & 1.09 & -0.53 \\
\hline & Z-bus & & 6.18 & 5.23 & 1.96 \\
\hline & PS & & 1.07 & 0.83 & 0.00 \\
\hline \multirow[t]{3}{*}{$5-6$} & Proposed & -0.49 & 1.44 & -0.14 & -1.79 \\
\hline & Z-bus & & 4.35 & 1.35 & -1.38 \\
\hline & PS & & -0.03 & -0.14 & -0.34 \\
\hline \multirow{3}{*}{$\begin{array}{l}\text { Total transmission } \\
\text { cost }(\$ / \mathrm{h})\end{array}$} & Proposed & & 498.70 & 400.10 & 406.20 \\
\hline & Z-bus & & 895.70 & 560.30 & 347.20 \\
\hline & PS & & 553.10 & 474.30 & 277.60 \\
\hline \multirow[t]{3}{*}{ Tariffs (\$/MWh) } & Proposed & & 9.97 & 9.40 & 9.02 \\
\hline & Z-bus & & 17.91 & 13.16 & 7.72 \\
\hline & PS & & 11.06 & 11.14 & 6.17 \\
\hline
\end{tabular}

branches. This fact holds for each time step considered. For example, under the proposed method, the generator at bus 1 as the closest one to the sending-end bus of the lines 1-2, $1-4$, and $1-5$, has the highest direct contribution to the power flow of those lines. The generator at bus 2 , as the
Table 4 Time series study of three TCA methods on 6-bus test system (time step 2)

\begin{tabular}{|c|c|c|c|c|c|}
\hline \multirow[t]{2}{*}{ Line number } & \multirow{2}{*}{$\begin{array}{l}\text { TCA } \\
\text { method }\end{array}$} & \multicolumn{4}{|c|}{ Power flow contribution (MW) } \\
\hline & & $P_{\text {line }}$ & G1 & $\mathrm{G} 2$ & G3 \\
\hline \multirow[t]{3}{*}{$1-2$} & Proposed & 7.89 & 9.96 & -2.14 & 0.08 \\
\hline & Z-bus & & 18.17 & -6.07 & -1.52 \\
\hline & PS & & 7.89 & 0.00 & 0.00 \\
\hline \multirow[t]{3}{*}{$1-4$} & Proposed & 21.35 & 11.28 & 4.39 & 5.69 \\
\hline & Z-bus & & 16.08 & 0.26 & 1.06 \\
\hline & PS & & 21.35 & 0.00 & 0.00 \\
\hline \multirow[t]{3}{*}{$1-5$} & Proposed & 20.75 & 10.20 & 6.02 & 4.53 \\
\hline & Z-bus & & 15.75 & 5.82 & 0.46 \\
\hline & PS & & 20.75 & 0.00 & 0.00 \\
\hline \multirow[t]{3}{*}{$2-3$} & Proposed & 3.03 & 3.13 & 5.04 & -5.14 \\
\hline & Z-bus & & 7.10 & 11.22 & -7.87 \\
\hline & PS & & 0.36 & 2.68 & 0.00 \\
\hline \multirow[t]{3}{*}{$2-4$} & Proposed & 29.10 & 3.30 & 14.03 & 11.76 \\
\hline & Z-bus & & -4.03 & 13.77 & 5.89 \\
\hline & PS & & 3.47 & 25.66 & 0.00 \\
\hline \multirow[t]{3}{*}{$2-5$} & Proposed & 15.33 & 3.56 & 7.53 & 4.23 \\
\hline & Z-bus & & 3.82 & 10.23 & 1.29 \\
\hline & PS & & 1.83 & 13.51 & 0.00 \\
\hline \multirow[t]{3}{*}{$2-6$} & Proposed & 18.70 & 6.46 & 9.98 & 2.26 \\
\hline & Z-bus & & 7.53 & 12.52 & -4.23 \\
\hline & PS & & 2.23 & 16.49 & 0.00 \\
\hline \multirow[t]{3}{*}{$3-5$} & Proposed & 18.03 & 1.62 & 4.42 & 11.99 \\
\hline & Z-bus & & 0.60 & 4.41 & 14.80 \\
\hline & PS & & 0.14 & 1.00 & 16.90 \\
\hline \multirow[t]{3}{*}{$3-6$} & Proposed & 30.02 & 4.76 & 6.58 & 18.68 \\
\hline & Z-bus & & 0.70 & 0.22 & 16.92 \\
\hline & PS & & 0.23 & 1.67 & 28.15 \\
\hline \multirow[t]{3}{*}{$4-5$} & Proposed & 4.46 & 1.91 & 2.24 & 0.31 \\
\hline & Z-bus & & 6.22 & 7.09 & 1.90 \\
\hline & PS & & 2.24 & 2.31 & 0.00 \\
\hline \multirow[t]{3}{*}{$5-6$} & Proposed & -2.96 & 0.69 & -0.94 & -2.71 \\
\hline & Z-bus & & 4.29 & 1.80 & -1.30 \\
\hline & PS & & -0.15 & -1.14 & -1.77 \\
\hline \multirow{3}{*}{$\begin{array}{l}\text { Total transmission } \\
\text { cost }(\$ / \mathrm{h})\end{array}$} & Proposed & & 454.10 & 474.00 & 376.90 \\
\hline & Z-bus & & 817.90 & 655.80 & 305.70 \\
\hline & PS & & 507.90 & 541.80 & 255.20 \\
\hline \multirow[t]{3}{*}{ Tariffs (\$/MWh) } & Proposed & & 9.08 & 8.13 & 8.37 \\
\hline & Z-bus & & 16.36 & 11.24 & 6.78 \\
\hline & PS & & 10.16 & 9.29 & 5.66 \\
\hline
\end{tabular}

sending-end bus of the lines 2-3, 2-4, 2-5, and 2-6, incorporates most in their associated power flows. The same principle holds for the lines 3-6, 4-5 and 5-6. This property may be called the nearby effect of the power networks most evident in the PS method. 
Table 5 Time series study of three TCA methods on 6-bus test system (time step 3)

\begin{tabular}{|c|c|c|c|c|c|}
\hline \multirow[t]{2}{*}{ Line number } & \multirow{2}{*}{$\begin{array}{l}\text { TCA } \\
\text { method }\end{array}$} & \multicolumn{4}{|c|}{ Power flow contribution (MW) } \\
\hline & & $P_{\text {line }}$ & G1 & $\mathrm{G} 2$ & G3 \\
\hline \multirow[t]{3}{*}{$1-2$} & Proposed & 5.87 & 9.69 & -3.38 & -0.44 \\
\hline & Z-bus & & 18.47 & -7.80 & -2.07 \\
\hline & PS & & 5.87 & 0.00 & 0.00 \\
\hline \multirow[t]{3}{*}{$1-4$} & Proposed & 23.90 & 11.46 & 5.57 & 6.86 \\
\hline & Z-bus & & 15.93 & 0.35 & 1.44 \\
\hline & PS & & 23.90 & 0.00 & 0.00 \\
\hline \multirow[t]{3}{*}{$1-5$} & Proposed & 20.23 & 9.58 & 6.45 & 4.20 \\
\hline & Z-bus & & 15.60 & 7.44 & 0.63 \\
\hline & PS & & 20.23 & 0.00 & 0.00 \\
\hline \multirow[t]{3}{*}{$2-3$} & Proposed & 1.18 & 2.56 & 5.71 & -7.09 \\
\hline & Z-bus & & 7.07 & 14.22 & -10.80 \\
\hline & PS & & 0.09 & 1.09 & 0.00 \\
\hline \multirow[t]{3}{*}{$2-4$} & Proposed & 40.39 & 4.90 & 19.55 & 15.94 \\
\hline & Z-bus & & -3.83 & 17.60 & 8.02 \\
\hline & PS & & 2.96 & 37.45 & 0.00 \\
\hline \multirow[t]{3}{*}{$2-5$} & Proposed & 16.40 & 3.28 & 8.80 & 4.32 \\
\hline & Z-bus & & 3.90 & 13.02 & 1.87 \\
\hline & PS & & 1.20 & 15.20 & 0.00 \\
\hline \multirow[t]{3}{*}{$2-6$} & Proposed & 22.24 & 6.64 & 12.77 & 2.83 \\
\hline & Z-bus & & 7.60 & 15.99 & -5.69 \\
\hline & PS & & 1.63 & 20.62 & 0.00 \\
\hline \multirow[t]{3}{*}{$3-5$} & Proposed & 20.87 & 1.62 & 5.10 & 14.15 \\
\hline & Z-bus & & 0.59 & 5.58 & 19.53 \\
\hline & PS & & 0.03 & 0.37 & 20.48 \\
\hline \multirow[t]{3}{*}{$3-6$} & Proposed & 40.64 & 6.22 & 9.81 & 24.61 \\
\hline & Z-bus & & 0.67 & 0.22 & 22.77 \\
\hline & PS & & 0.06 & 0.72 & 39.89 \\
\hline \multirow[t]{3}{*}{$4-5$} & Proposed & 2.53 & 1.29 & 1.85 & -0.62 \\
\hline & Z-bus & & 6.21 & 9.02 & 2.61 \\
\hline & PS & & 1.08 & 1.51 & 0.00 \\
\hline \multirow[t]{3}{*}{$5-6$} & Proposed & -1.70 & 1.08 & -0.37 & -2.41 \\
\hline & Z-bus & & 4.27 & 2.32 & -1.85 \\
\hline & PS & & -0.05 & -0.60 & -1.12 \\
\hline \multirow{3}{*}{$\begin{array}{l}\text { Total } \\
\text { transmission } \\
\text { cost }(\$ / \mathrm{h})\end{array}$} & Proposed & & 423.40 & 501.10 & 380.50 \\
\hline & Z-bus & & 738.80 & 714.40 & 341.90 \\
\hline & PS & & 468.90 & 564.40 & 271.60 \\
\hline \multirow[t]{3}{*}{ Tariffs (\$/MWh) } & Proposed & & 8.47 & 6.74 & 6.30 \\
\hline & Z-bus & & 14.77 & 9.61 & 5.66 \\
\hline & PS & & 9.38 & 7.59 & 4.50 \\
\hline
\end{tabular}

To gain deeper insight into the results, the three methods are also compared in terms of counter flows. Tables 3, 4, 5 and 6 shows that both circuit-theory-based methods take into account the counter-flows, while this feature does not exist for the PS method. The proposed method, however,
Table 6 Time series study of three TCA methods on 6-bus test system (time step 4)

\begin{tabular}{|c|c|c|c|c|c|}
\hline \multirow[t]{2}{*}{ Line number } & \multirow{2}{*}{$\begin{array}{l}\text { TCA } \\
\text { method }\end{array}$} & \multicolumn{4}{|c|}{ Power flow contribution (MW) } \\
\hline & & $P_{\text {line }}$ & G1 & $\mathrm{G} 2$ & G3 \\
\hline \multirow[t]{3}{*}{$1-2$} & Proposed & 15.41 & 16.27 & -1.69 & 0.83 \\
\hline & Z-bus & & 28.14 & -7.27 & -2.35 \\
\hline & PS & & 15.41 & 0.00 & 0.00 \\
\hline \multirow[t]{3}{*}{$1-4$} & Proposed & 33.95 & 17.70 & 7.48 & 8.76 \\
\hline & Z-bus & & 24.80 & 0.43 & 1.64 \\
\hline & PS & & 33.95 & 0.00 & 0.00 \\
\hline \multirow[t]{3}{*}{$1-5$} & Proposed & 27.86 & 14.67 & 7.67 & 5.53 \\
\hline & Z-bus & & 24.28 & 6.84 & 0.72 \\
\hline & PS & & 27.86 & 0.00 & 0.00 \\
\hline \multirow[t]{3}{*}{$2-3$} & Proposed & 0.29 & 3.99 & 4.60 & -8.31 \\
\hline & Z-bus & & 11.03 & 12.91 & -12.70 \\
\hline & PS & & 0.05 & 0.24 & 0.00 \\
\hline \multirow[t]{3}{*}{$2-4$} & Proposed & 41.74 & 4.63 & 19.85 & 17.26 \\
\hline & Z-bus & & -6.23 & 16.55 & 9.37 \\
\hline & PS & & 7.62 & 34.25 & 0.00 \\
\hline \multirow[t]{3}{*}{$2-5$} & Proposed & 17.35 & 3.95 & 8.77 & 4.63 \\
\hline & Z-bus & & 5.94 & 12.03 & 2.18 \\
\hline & PS & & 3.17 & 14.24 & 0.00 \\
\hline \multirow[t]{3}{*}{$2-6$} & Proposed & 25.03 & 9.13 & 12.78 & 3.12 \\
\hline & Z-bus & & 11.70 & 14.99 & -6.66 \\
\hline & PS & & 4.57 & 20.54 & 0.00 \\
\hline \multirow[t]{3}{*}{$3-5$} & Proposed & 23.18 & 1.34 & 5.77 & 16.07 \\
\hline & Z-bus & & 0.93 & 5.06 & 22.81 \\
\hline & PS & & 0.02 & 0.08 & 23.10 \\
\hline \multirow[t]{3}{*}{$3-6$} & Proposed & 47.50 & 7.52 & 11.63 & 28.34 \\
\hline & Z-bus & & 1.08 & 0.00 & 26.55 \\
\hline & PS & & 0.04 & 0.16 & 47.32 \\
\hline \multirow[t]{3}{*}{$4-5$} & Proposed & 3.21 & 1.91 & 1.92 & -0.62 \\
\hline & Z-bus & & 9.44 & 8.60 & 3.01 \\
\hline & PS & & 1.82 & 1.50 & 0.00 \\
\hline \multirow[t]{3}{*}{$5-6$} & Proposed & -0.90 & 1.98 & -0.37 & -2.52 \\
\hline & Z-bus & & 6.55 & 2.26 & -2.13 \\
\hline & PS & & -0.06 & -0.27 & -0.62 \\
\hline \multirow{3}{*}{$\begin{array}{l}\text { Total } \\
\text { transmission } \\
\text { cost }(\$ / \mathrm{h})\end{array}$} & Proposed & & 475.70 & 444.70 & 384.60 \\
\hline & Z-bus & & 885.30 & 574.80 & 344.30 \\
\hline & PS & & 546.60 & 481.40 & 277.00 \\
\hline \multirow[t]{3}{*}{ Tariffs (\$/MWh) } & Proposed & & 6.16 & 6.42 & 5.46 \\
\hline & Z-bus & & 11.46 & 8.30 & 4.89 \\
\hline & PS & & 7.08 & 6.95 & 3.93 \\
\hline
\end{tabular}

smooths the trend of Z-bus method to reflect the counterflows. For example, in time step 4 representing the system peak condition, the contribution of the generator at bus 1 into the power flow of the line 5-6, is $6.55 \mathrm{MW}$ counterflow under the Z-bus method, and is $1.99 \mathrm{MW}$ counter- 
Table 7 6-bus test system cost allocation to buses

\begin{tabular}{|c|c|c|c|c|c|c|}
\hline \multirow[t]{2}{*}{ Line } & \multirow[t]{2}{*}{ Method } & \multicolumn{3}{|c|}{$\begin{array}{l}\text { Cost allocation to } \\
\text { generator bus }(\$ / \mathrm{h})\end{array}$} & \multirow{2}{*}{$\begin{array}{l}\text { Cost } \\
\text { allocation } \\
\text { to load } \\
\text { buses } 4-6 \\
(\$ / h)\end{array}$} & \multirow[t]{2}{*}{$\begin{array}{l}\text { Total } \\
(\$ / \mathrm{h})\end{array}$} \\
\hline & & Bus 1 & Bus 2 & Bus 3 & & \\
\hline \multirow[t]{3}{*}{$1-2$} & Proposed & 95.14 & 0 & 4.86 & 100 & 200 \\
\hline & Z-bus & 181.73 & 0 & 0 & 18.27 & \\
\hline & PS & 100 & 0 & 0 & 100 & \\
\hline \multirow[t]{3}{*}{$1-4$} & Proposed & 52.14 & 22.05 & 25.81 & 100 & 200 \\
\hline & Z-bus & 129.19 & 2.23 & 8.53 & 60.05 & \\
\hline & PS & 100 & 0 & 0 & 100 & \\
\hline \multirow[t]{3}{*}{$1-5$} & Proposed & 78.96 & 41.28 & 29.76 & 150 & 300 \\
\hline & Z-bus & 193.16 & 54.41 & 5.69 & 46.74 & \\
\hline & PS & 150 & 0 & 0 & 150 & \\
\hline \multirow[t]{3}{*}{$2-3$} & Proposed & 58.07 & 66.93 & 0 & 125 & 250 \\
\hline & Z-bus & 104.28 & 122.08 & 0 & 23.64 & \\
\hline & PS & 22.74 & 102.26 & 0 & 125 & \\
\hline \multirow[t]{3}{*}{$2-4$} & Proposed & 5.55 & 23.77 & 20.68 & 50 & 100 \\
\hline & Z-bus & 0 & 27.60 & 15.63 & 56.77 & \\
\hline & PS & 9.10 & 40.90 & 0 & 50 & \\
\hline \multirow[t]{3}{*}{$2-5$} & Proposed & 34.15 & 75.83 & 40.02 & 150 & 300 \\
\hline & Z-bus & 62.66 & 126.97 & 23.00 & 87.37 & \\
\hline & PS & 27.29 & 122.71 & 0 & 150 & \\
\hline \multirow[t]{3}{*}{$2-6$} & Proposed & 36.49 & 51.06 & 12.45 & 100 & 200 \\
\hline & Z-bus & 50.93 & 65.26 & 0 & 83.81 & \\
\hline & PS & 18.19 & 81.81 & 0 & 100 & \\
\hline \multirow[t]{3}{*}{$3-5$} & Proposed & 7.51 & 32.35 & 90.14 & 130 & 260 \\
\hline & Z-bus & 6.47 & 35.25 & 158.79 & 59.49 & \\
\hline & PS & 0.10 & 0.43 & 129.47 & 130 & \\
\hline \multirow[t]{3}{*}{$3-6$} & Proposed & 7.91 & 12.25 & 29.84 & 50 & 100 \\
\hline & Z-bus & 2.14 & 0 & 52.53 & 45.33 & \\
\hline & PS & 0.04 & 0.17 & 49.80 & 50 & \\
\hline \multirow[t]{3}{*}{$4-5$} & Proposed & 99.82 & 100.18 & 0 & 200 & 400 \\
\hline & Z-bus & 154.73 & 140.96 & 49.31 & 55.00 & \\
\hline & PS & 109.65 & 90.35 & 0 & 200 & \\
\hline \multirow[t]{3}{*}{$5-6$} & Proposed & 0 & 19.03 & 130.97 & 150 & 300 \\
\hline & Z-bus & 0 & 0 & 30.83 & 269.17 & \\
\hline & PS & 9.51 & 42.75 & 97.74 & 150 & \\
\hline \multirow{3}{*}{$\begin{array}{l}\text { Network } \\
\text { cost }\end{array}$} & Proposed & 475.74 & 444.73 & 384.53 & 1305 & 2610 \\
\hline & Z-bus & 885.29 & 574.76 & 344.31 & 805.64 & \\
\hline & PS & 546.62 & 481.38 & 277.01 & 1305 & \\
\hline \multirow{3}{*}{$\begin{array}{l}\text { Tariffs } \\
\text { (\$/ } \\
\text { MWh) }\end{array}$} & Proposed & 6.16 & 6.42 & 5.46 & & \\
\hline & Z-bus & 11.46 & 8.30 & 4.89 & & \\
\hline & PS & 7.08 & 6.95 & 3.93 & & \\
\hline
\end{tabular}

flow, under the proposed method. In the same time step, given the generator at bus 2, there exists a counter-flow contribution of the generator into the power flow of line 1-2, with 7.27 MW and 1.69 MW under the Z-bus and the proposed methods, respectively. Note that, higher counter flows with excessive rewards may result in unfair competition, and in turn, may distort the power market.

Table 7 depicts, in detail, the allocated transmission use of system (TUoS) costs and tariffs of the generators based on the partial branch power flows obtained in the system peak condition (time step 4 in Table 6). As shown in Table 7, each branch cost is allocated by $50-50$ ratio between the generators and loads, under the proposed as well as PS methods, in spite of different allocated cost distributions among the generators as a result of different partial branch power flows assigned to the generators under these methods, previously addressed in Tables 3, 4, 5 and 6. In contrast, for Z-bus method it is basically the network parameters that determine the ratio by which the costs are allocated between the generators and loads. For instance, the cost of lines $1-5$ and 5-6 both equals $300 \$ / \mathrm{h}$. The proposed technique, as with the PS methodology, assigns $150 \$ / \mathrm{h}(50 \%)$ of each line cost to the generators. Under the Z-bus method, however, $253.26 \$ / \mathrm{h}$ of line $1-5$ cost is allocated to the generators and $46.74 \$ / \mathrm{h}$ to the loads, and for line 5-6, the share of the generators and loads become $30.83 \$ / h$ and $269.17 \$ / h$, respectively.

Based on the results shown in Table 7, it is confirmed that the proposed method considers the amount, the location and the effective use of the line by the generators in its allocation process. For example, the generator at bus 2 uses the line 1-2 less, compared to the generator at bus 1 , due to the power flow direction of the line 1-2. These properties hold for the proposed method, irrespective of the pricing method applied, that is ZCF, absolute value (AV) and classic MW-mile pricing. For example, under the proposed method, the network costs of the generators using the ZCF pricing are $475.74 \$ / \mathrm{h}, 444.73 \$ / \mathrm{h}$ and $384.53 \$ / \mathrm{h}$, while these values change slightly to $485.86 \$ / \mathrm{h}, 399.09 \$ / \mathrm{h}$ and $420.04 \$ / h$, if the AV pricing is used. In case of the Z-bus method, however, the results change significantly, when different pricing schemes are used. The network costs allocated to the generators are $885.29 \$ / \mathrm{h}, 574.75 \$ / \mathrm{h}$ and $344.31 \$ / \mathrm{h}$, by the ZCF pricing, where these values become $668.43 \$ / \mathrm{h}, 412.85 \$ / \mathrm{h}$ and $337.77 \$ / \mathrm{h}$, by the AV pricing method. Discrepancies arise because significant counterflows exist under the Z-bus method.

According to Table 7 and considering the TUoS tariffs of the generators, under each of the three methods, the generator at bus 3 pays the lowest price, whereas the generator at bus 1 has to pay the highest price, for the use of the network. However, the TUoS tariffs of the generators at buses 1 and 2 are relatively high according to the Z-bus method, because $69.13 \%$ of the network cost is imposed to the generators.

The proposed method is less sensitive to the calculation reference side of the lines compared with the Z-bus 
method, for which the results change significantly when the calculation reference side is changed. For example, under the proposed method, when $P_{1-2}$ is considered as reference, the power flow contribution and the allocated cost to the generator at bus 1 due to the line 1-2, are 16.27 MW and $95.14 \$ / \mathrm{h}$, whereas the values change slightly to 15.93 MW and $95.00 \$ / \mathrm{h}$ when $P_{2-1}$ is considered as reference. When Z-bus is used to calculate the same quantities, the values become $28.14 \mathrm{MW}$ and $181.72 \$ / \mathrm{h}$ for $P_{1-2}$ being considered as reference, whereas they change significantly to $22.43 \mathrm{MW}$ and $125.69 \$ / \mathrm{h}$ when $P_{2-1}$ is considered as reference.

\subsection{IEEE 30-bus system}

To validate the proposed method, the IEEE 30-bus system illustrated in Fig. 2 is used as a test system. Branch data are provided in [37]. Bus data for the base case are provided in Appendix A Table A1.

\subsubsection{Contribution of generators into branch power flows}

The generators are located at buses 1, 2, 22, 27, 23, 13 . Figures 3 and 4 illustrate the contributions of the generators into the network real power flow of the branches applied by the three cost allocation methods including Z-bus theory, PS method represented by Bialek, and the proposed method.

According to Figs. 3 and 4, the following contributions are obtained:

1) The overall contribution profiles of the generators for the three methods are almost comparable, i.e. the power flow contribution of the generators into the neighboring lines is higher compared to the others calculated by each of the three methods, although they have different principles. The generators at buses 1 and 2 contribute most in lines 1-15 (Fig. 3a and b). Likewise, for the generators connected at bus numbers 22, 27, 23 and 13, their associated lines with dominant power flow contribution of the corresponding generators are: line numbers 25-29 for G22; 26-41 for G27; 22, 30, 32 for G23; 16-18 for G13, according to Figs. 3c, d, $4 \mathrm{a}$ and $\mathrm{b}$, respectively. It may be entitled "the nearby effects of the power networks".

2) The curves obtained by the PS theory have several lines with zero contribution of the generators. This is because the PS theory does not consider the counterflow effects in its calculations despite the fact that the concept of counter-flows is indispensable in power flow related problems.

Figure 5 shows the real power flow allocation of two high loaded branches 1-2 and 6-8. The results are more

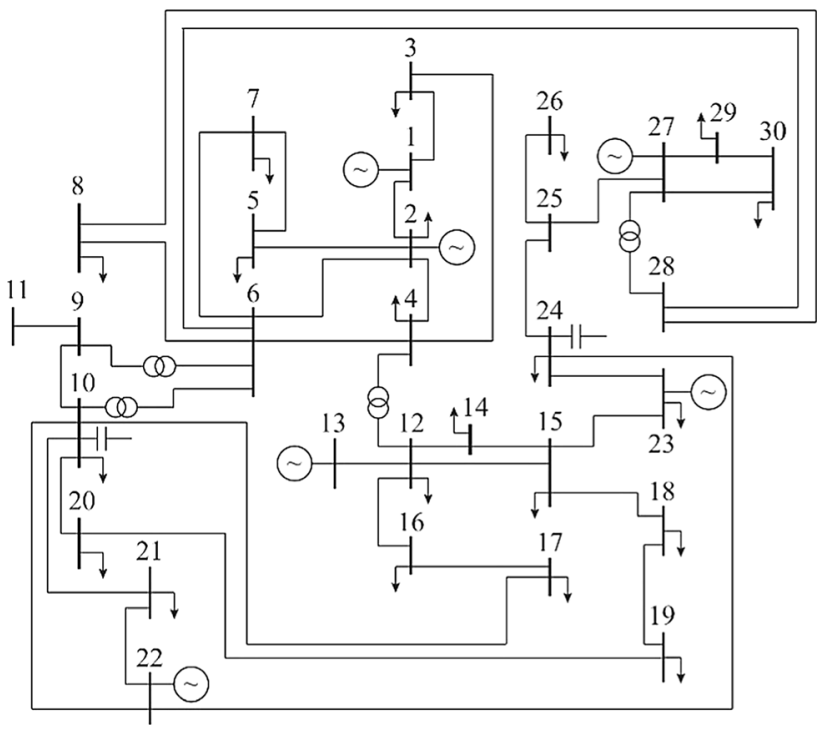

Fig. 2 IEEE 30-bus test system

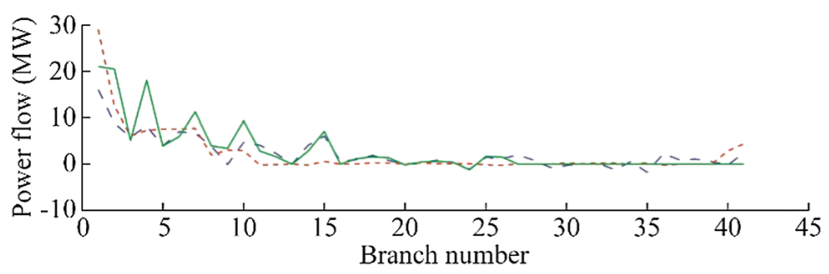

(a) G1 contribution

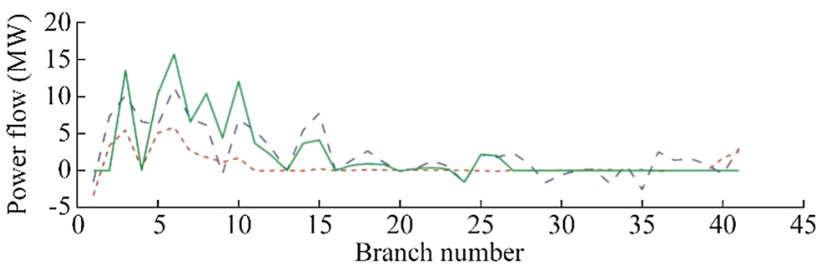

(b) G2 contribution

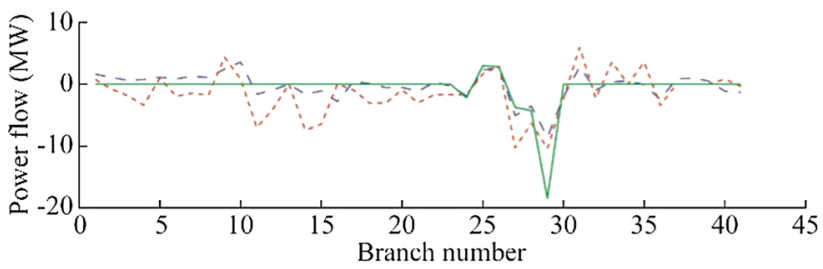

(c) G22 contribution

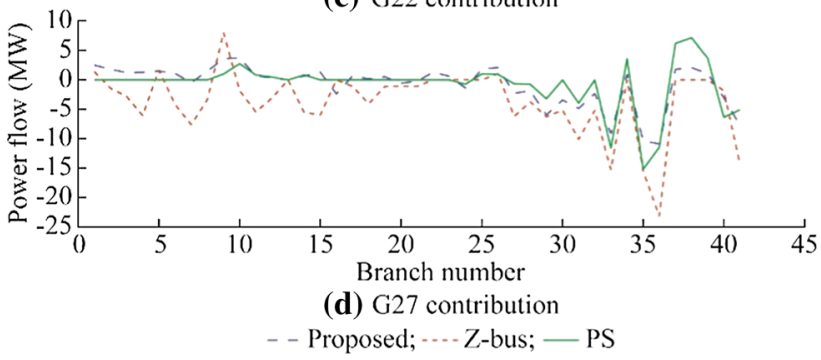

Fig. 3 Contribution of generators G1, G2, G22 and G27 into branch power flows of IEEE 30-bus system 


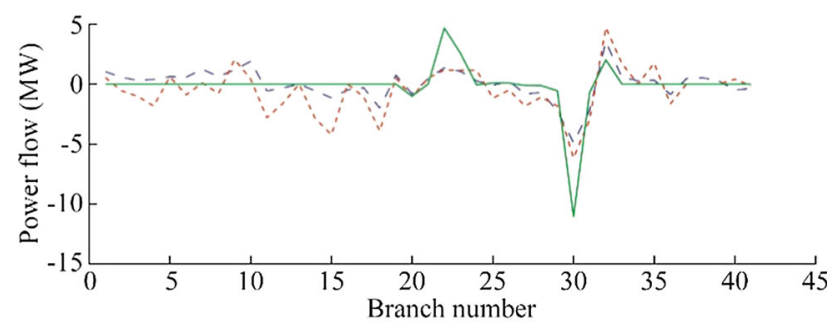

(a) G23 contribution

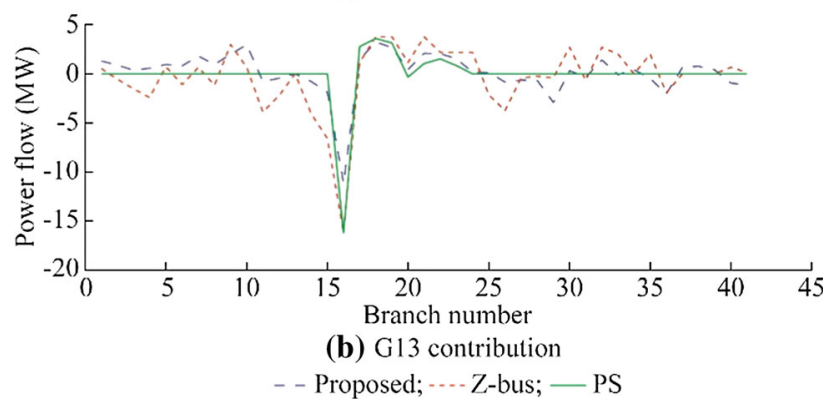

Fig. 4 Contribution of generators G23 and G13 into branch power flows of IEEE 30-bus system

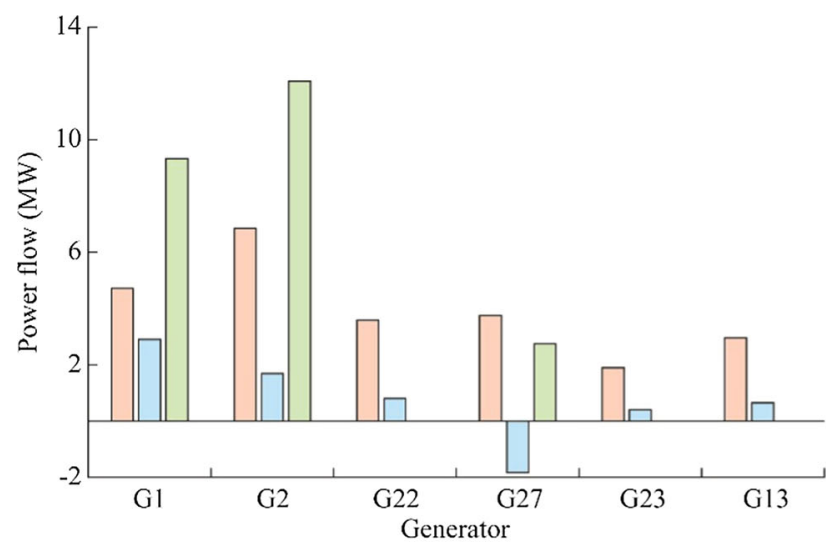

(a) Branch 6-8

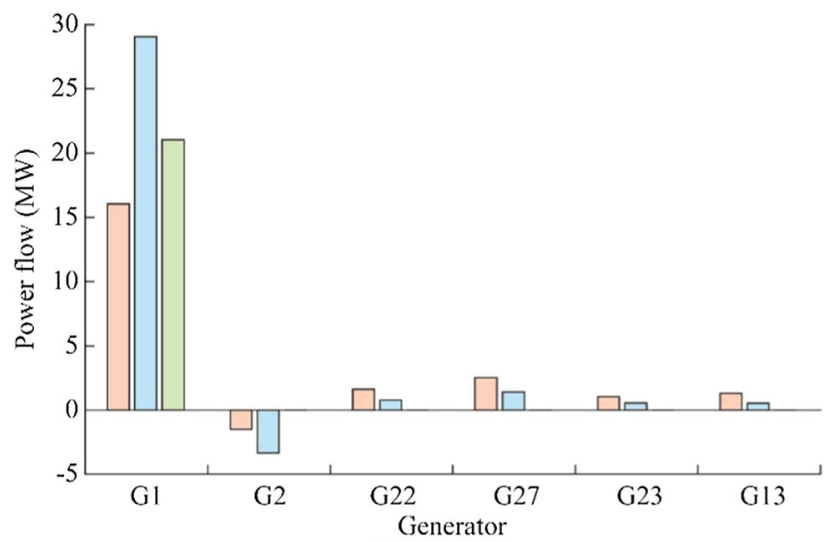

(b) Branch 1-2

$\varpi$ Proposed; $\square$ Z-bus; $\square$ PS

Fig. 5 Partial power flows of branches 6-8 and 1-2 due to generators locational by the PS method (Fig. 5a) thanks to the proportional sharing principle which has no counter-flow effect consideration. They are more intense by the Z-bus method in case of high counter-flow shares of some generators (Fig. 5b), and modest by the proposed method. Discrepancies arise by the fact that Z-bus method uses the current flows while the proposed method applies the power flows to allocate.

For branch 6-8, each of the three methods allocate the highest contribution to the generators located at buses 1 and 2. The share of the generators located at buses other than 1 and 2 is completely different for the three methods. The PS allocation scheme is completely based on the power flow directions of the lines. Among the generators located at the buses 22, 27, 23 and 13, only G27 contributes into the power flow of the branch 6-8 because there is a path from the generator at the bus 27 to the sending end of the branch 6-8 (the path is 27-28, 28-6) with the same direction as the real power flow of the branches. For the Z-bus methodology, the contribution of the generators into the branch flows is highly dependent on their neighboring loads since the method traces the current flow of the participants. In the proposed methodology, it is the overall location of the generators with respect to the loads that determines the outcomes, which makes the generator tariffs more stable compared to the other two methods (Table 8).

For branch 1-2 (Fig. 5b), the contribution of the generator located at bus 1 is dominant by each of the three methods as G1 is connected to the sending end of the line 1-2. Since the counter-flows are not considered in PS method, the adjacent generator G2 located at bus 2 has no share in the power flow of the line 1-2. For the Z-bus method, the share of generator 1 in power flow of the line 1-2 exceeds the real power flow of the line by an amount almost equal to the generator G2's significant counter-flow contribution into the line 1-2. In case of the proposed method, the counter-flow share of the generator G2 is lower and the G1 has a moderate contribution amount into the power flow of the line 1-2.

\subsubsection{Generator buses' TUoS charges}

Table 8 lists the transmission per-unit costs allocated to the generator buses for the base case and the cases with individual loads altered. $P_{1}(b)$ in $\mathrm{MW}$ is the active power of the load connected to the bus $b$.

According to Table 8, for the base case, bus numbers 1 , 2 and 22 have TUoS tariffs cheaper than buses 27, 23 and 13 calculated by all the three methods, because large loads 
are connected at buses $2,7,8$ and 21 . The generators G1 and G2 tariffs are highly dependent on the large loads connected at the buses 2,7 and 8 . Thus, minor changes take place by varying the loads connected at buses relatively far from that units. This statement is shown in the Table 8 by altering the loads connected at buses 21, 12, 30, 23 and 27. The highest TUoS tariff is assigned to the bus 27 by the PS method due to its relative distance from the large loads and to bus 13 by the proposed method due to its circuit condition characterized by the voltage and current equations of the networks. For Z-bus method, the high tariff buses have almost the same prices. The generator connected at bus 22 close to the load bus 21, have the lowest TUoS tariff by the PS method whereas its tariff is equal to the G1 and G2 charges by the proposed method due to their similar circuit conditions.

Among the methods discussed, the proposed method has the highest tariff stability against the single load variations. If the load on bus 21 with the real power demand of 17.5 MW is disconnected from the network, the TUoS charges of the generator buses 22, 27 and 23 located in the neighboring zone of bus 21 will be changed by the three methods. The tariff variation of the generator 22 is $+13 \$$ / MW (36\%) for the proposed method, + 14 \$/MW (54\%)

Table 8 Comparison of TUoS tariffs of generator buses for some operating points on IEEE 30-bus test system

\begin{tabular}{|c|c|c|c|c|c|c|c|}
\hline \multirow[t]{2}{*}{ Operating point } & \multirow[t]{2}{*}{ Method } & \multicolumn{6}{|c|}{$\begin{array}{l}\text { Transmission cost per-unit of generator } \\
\text { bus (\$/MWh) }\end{array}$} \\
\hline & & G1 & G2 & G22 & G27 & G23 & G13 \\
\hline \multirow[t]{3}{*}{ Base case } & Proposed & 34 & 34 & 36 & 51 & 48 & 63 \\
\hline & Z-bus & 38 & 37 & 26 & 51 & 52 & 54 \\
\hline & PS & 33 & 24 & 15 & 85 & 53 & 44 \\
\hline \multirow[t]{3}{*}{$P_{1}(21)=0$} & Proposed & 36 & 36 & 49 & 62 & 39 & 66 \\
\hline & Z-bus & 41 & 39 & 40 & 63 & 42 & 51 \\
\hline & PS & 33 & 24 & 33 & 101 & 41 & 43 \\
\hline \multirow[t]{3}{*}{$P_{1}(12)=0$} & Proposed & 35 & 36 & 39 & 55 & 50 & 69 \\
\hline & Z-bus & 41 & 39 & 28 & 54 & 54 & 59 \\
\hline & PS & 34 & 24 & 15 & 89 & 54 & 60 \\
\hline \multirow[t]{3}{*}{$P_{1}(30)=20 \mathrm{MW}$} & Proposed & 32 & 32 & 33 & 47 & 44 & 60 \\
\hline & Z-bus & 37 & 35 & 25 & 46 & 47 & 51 \\
\hline & PS & 32 & 24 & 15 & 71 & 51 & 43 \\
\hline \multirow[t]{3}{*}{$P_{1}(23)=20 \mathrm{MW}$} & Proposed & 33 & 32 & 34 & 50 & 36 & 51 \\
\hline & Z-bus & 37 & 35 & 27 & 51 & 34 & 42 \\
\hline & PS & 33 & 24 & 15 & 91 & 16 & 41 \\
\hline \multirow[t]{3}{*}{$P_{1}(27)=20 \mathrm{MW}$} & Proposed & 33 & 35 & 28 & 42 & 36 & 53 \\
\hline & Z-bus & 39 & 37 & 22 & 41 & 39 & 45 \\
\hline & PS & 34 & 24 & 16 & 60 & 41 & 42 \\
\hline
\end{tabular}

for the Z-bus method and +18.1 \$MW (121\%) for the PS method. For the generator 27, the tariff growths are $+11 \$ /$ MW $(22 \%)$ by the proposed method, $+12 \$ / \mathrm{MW}(24 \%)$ by the Z-bus method and $+16 \$ / \mathrm{MW}(20 \%)$ by the PS method. The tariff decrease of the generator bus 23 is $19 \%$ for both the proposed and the Z-bus method and $22 \%$ for the PS method. The same scenario takes place in case of the load increase at buses 30, 23 and 27. For example, the highest tariff variation due to the $10 \mathrm{MW}$ load growth of bus 30 is associated to bus 27 calculated by the PS method, which is a $14 \$ / \mathrm{MW}$ decrease from 85 to $71 \$ / \mathrm{MW}$.

\subsection{3-bus practical system}

Tables 9,10 and 11 presents the results obtained by applying the proposed method to the Polish 2383-bus system. To emphasize that the proposed method is applicable to very large systems, the 2383-bus system of Polish 400, 220 and $110 \mathrm{kV}$ networks during winter 1999-2000 peak conditions is considered. The system data are given in MATPOWER user's manual. The proposed method does not encounter the singularity problems of the Z-bus method to build the impedance matrix as well as the PS method to build the inverted tracing distribution matrices. An Intel Core i5, $2.3 \mathrm{GHz}, 6$ GB RAM 64-bit computer is used to run the simulations of this system. MATLAB R2016a reported the elapsed time $18.73 \mathrm{~s}$ which is fairly a short running time. It is noted that in Table 11, APG represents the active power generated; TTPU/TTNU represent the

Table 9 First 5 branches with highest tariffs

\begin{tabular}{lcl}
\hline Branch & Power flow $(\mathrm{MW})$ & Tariffs $(\$ / \mathrm{h})$ \\
\hline $1764-1760$ & 16.54 & 463.20 \\
$1763-1761$ & 38.19 & 452.50 \\
$612-413$ & 63.46 & 324.00 \\
$1945-1845$ & -40.60 & 245.50 \\
$1489-1426$ & -69.30 & 237.20 \\
\hline
\end{tabular}

Table 10 First 5 branches with highest power flows

\begin{tabular}{lcc}
\hline Branch & Power flow $(\mathrm{MW})$ & Tariffs $(\$ / \mathrm{h})$ \\
\hline $138-67$ & -771.20 & 20.56 \\
$32-31$ & -681.70 & 0.10 \\
$18-15$ & 552.20 & 42.62 \\
$15-165$ & 451.60 & 24.74 \\
$132-131$ & -416.50 & 0.10
\end{tabular}


Table 11 Transmission use of system related values for selected buses in Polish 2383-bus test system by proposed method

\begin{tabular}{|c|c|c|c|c|c|c|c|c|c|c|c|}
\hline \multirow{2}{*}{$\begin{array}{l}\text { No. } \\
1\end{array}$} & \multirow{2}{*}{$\begin{array}{l}\text { Bus number } \\
18\end{array}$} & \multicolumn{2}{|c|}{ APG (MW) } & \multicolumn{2}{|c|}{ TTPU (MW) } & \multicolumn{2}{|c|}{ TTNU (MW) } & \multicolumn{2}{|c|}{ TTC $(\$ / h)$} & \multicolumn{2}{|c|}{$\begin{array}{l}\text { TUoS charge } \\
(\$ / M W h)\end{array}$} \\
\hline & & \multicolumn{2}{|c|}{1908} & \multicolumn{2}{|c|}{9241} & \multicolumn{2}{|c|}{1342} & \multicolumn{2}{|c|}{6530} & \multicolumn{2}{|c|}{3.42} \\
\hline 2 & 17 & \multicolumn{2}{|c|}{1080} & \multicolumn{2}{|c|}{5910} & \multicolumn{2}{|c|}{623} & \multicolumn{2}{|c|}{4226} & \multicolumn{2}{|c|}{3.91} \\
\hline 3 & 31 & 10 & & & & 1336 & & & & & 93 \\
\hline 4 & 131 & 8 & & & & 1277 & & 44 & & & 08 \\
\hline 5 & 67 & 7 & & & & 882 & & 34 & & & 66 \\
\hline 6 & 16 & 7 & & & & 450 & & 27 & & & 78 \\
\hline 7 & 127 & 6 & & & & 931 & & 32 & & & 66 \\
\hline 8 & 63 & 6 & & & & 565 & & 25 & & & 86 \\
\hline 9 & 176 & 6 & & & & 1108 & & 28 & & & 72 \\
\hline 10 & 139 & 6 & & & & 828 & & 26 & & & 45 \\
\hline 11 & 1426 & 4 & & & & 706 & & 23 & & & 69 \\
\hline 12 & 64 & 4 & & & & 395 & & & & & 83 \\
\hline 13 & 105 & 4 & & & & 745 & & & & & 57 \\
\hline 14 & 43 & 4 & & & & 479 & & 16 & & & 10 \\
\hline 15 & 44 & 4 & & & & 558 & & & & & 11 \\
\hline 16 & 10 & 4 & & & & 775 & & & & & 96 \\
\hline 17 & 911 & 3 & & & & 493 & & 19 & & & 40 \\
\hline 18 & 912 & 3 & & & & 490 & & & & & 70 \\
\hline 19 & 1416 & 3 & & & & 807 & & & & & 25 \\
\hline 20 & 111 & 3 & & & & 409 & & & & & 38 \\
\hline 21 & 2164 & 4. & & & 1 & 15 & & & & & \\
\hline 22 & 2268 & 1.8 & & & 9 & 7 & & & & & \\
\hline 23 & 2328 & & 3 & & 3 & 7 & & & & & \\
\hline 24 & 2159 & & 2 & & & 75 & & & & & \\
\hline 25 & 132 & & 0 & & & 195 & & & & & \\
\hline & & Branch pow & er flow contri & sution of $\mathrm{g}$ & rator (MW) & & & & & & \\
\hline No. & Bus number & $1764-1760$ & $1763-1761$ & $612-413$ & $1945-1845$ & $1489-1426$ & $138-67$ & $32-31$ & $18-15$ & $15-165$ & $132-131$ \\
\hline 1 & 18 & 0.45 & 2.52 & 3.69 & -1.96 & -3.71 & -92.43 & -68.26 & 133.24 & 90.95 & -16.46 \\
\hline 2 & 17 & 0.30 & 2.02 & 2.89 & -1.07 & -2.14 & -41.81 & -28.13 & 55.10 & 39.11 & -6.80 \\
\hline 3 & 31 & 0.47 & 1.32 & 3.57 & -0.86 & -1.84 & -25.05 & -207.80 & -2.61 & 51.53 & -3.82 \\
\hline 4 & 131 & 0.55 & 0.21 & 0.84 & -2.45 & -0.51 & 43.14 & -8.20 & 12.98 & 5.88 & -257.60 \\
\hline 5 & 67 & 0.28 & 0.44 & 1.17 & -1.22 & -1.02 & -136.6 & -14.64 & 27.01 & 17.97 & -21.06 \\
\hline 6 & 16 & 0.18 & 1.35 & 1.80 & -0.73 & -1.47 & -28.34 & -19.64 & 37.20 & 26.16 & -4.74 \\
\hline 7 & 127 & 0.67 & 0.80 & 0.55 & -3.96 & -0.14 & -6.38 & -6.99 & -1.27 & -15.81 & 0.40 \\
\hline 8 & 63 & 0.15 & 0.48 & 1.48 & -0.35 & -3.20 & -20.38 & -13.31 & 17.66 & 14.97 & -3.14 \\
\hline 9 & 176 & 0.51 & 0.71 & 0.28 & -1.55 & -0.43 & -8.00 & -16.94 & -22.13 & -59.80 & -1.29 \\
\hline 10 & 139 & 1.62 & 3.68 & 1.05 & -1.16 & -0.43 & -7.96 & -8.50 & 3.67 & -3.86 & -2.64 \\
\hline 11 & 1426 & 0.11 & 0.32 & 1.13 & -0.21 & -25.47 & -11.99 & -9.90 & 10.48 & 10.03 & -1.68 \\
\hline 12 & 64 & 0.11 & 0.34 & 1.06 & -0.24 & -2.91 & -14.15 & -9.11 & 12.47 & 10.59 & -2.17 \\
\hline 13 & 105 & 0.11 & 0.48 & 0.99 & -0.39 & -0.79 & -20.30 & -13.41 & 19.94 & 16.22 & -3.82 \\
\hline 14 & 43 & 0.14 & 0.44 & 1.43 & -0.29 & -0.81 & -11.86 & -27.96 & 8.18 & 15.46 & -1.79 \\
\hline 15 & 44 & 0.14 & 0.44 & 1.43 & -0.29 & -0.81 & -11.85 & -28.04 & 8.17 & 15.47 & -1.79 \\
\hline 16 & 10 & 0.26 & 0.50 & -1.91 & -0.48 & -0.32 & -5.05 & -15.79 & -2.20 & 7.15 & -0.73 \\
\hline 17 & 911 & 0.12 & 0.22 & 0.60 & -0.49 & -0.54 & -47.78 & -7.21 & 12.55 & 8.56 & -8.43 \\
\hline 18 & 912 & 0.12 & 0.22 & 0.59 & -0.47 & -0.53 & -46.64 & -7.04 & 12.13 & 8.29 & -8.19 \\
\hline 19 & 1416 & 0.08 & 0.23 & 0.73 & -0.17 & 4.27 & -10.22 & -6.89 & 8.56 & 7.11 & -1.54 \\
\hline 20 & 111 & 0.57 & 1.94 & 0.83 & -0.59 & -0.33 & -6.66 & -5.50 & 6.36 & 2.64 & -1.55 \\
\hline 21 & 2164 & 0.00 & 0.01 & 0.00 & -0.02 & 0.00 & -0.06 & -0.05 & -0.02 & -0.15 & -0.01 \\
\hline 22 & 2268 & 0.00 & 0.00 & 0.00 & -0.01 & 0.00 & -0.02 & -0.02 & -0.01 & -0.07 & -0.01 \\
\hline 23 & 2328 & 0.00 & 0.00 & 0.00 & -0.01 & 0.00 & -0.04 & -0.03 & 0.01 & -0.08 & -0.01 \\
\hline 24 & 2159 & 0.00 & 0.03 & 0.07 & -0.03 & 0.05 & 0.18 & 0.89 & 2.26 & 3.51 & 0.05 \\
\hline 25 & 132 & 0.01 & 0.31 & -0.07 & -0.57 & 0.12 & -19.47 & 2.59 & -0.55 & 1.90 & 7.44 \\
\hline
\end{tabular}


sum of partial branch power flows due to a generator in the same/opposite direction to branch power flow, respectively. The first 20 rows (No. 1-20) of Table 11 show the first 20 generators in terms of APG, TTPU and TTC. The last 5 rows (No. 21-25) of Table 11 show the first 5 generators in terms of TUoS tariffs.

\section{Conclusion}

This paper presents a new circuit-theory-based method to the problem of TCA. Unlike majority, if not all, similar methods, the proposed method attempts to justify the way it treats the non-linear behavior of the power systems to mathematically identify the shares of the participants on network power quantities. The applied principle to split the mutual terms of the power equations, as the causes of nonlinearity, is confirmed by the Shapley and Aumann-Shapley values as the preferred transmission network cost game solutions. Moreover, a new concept, named circuit-theorybased EBE, is introduced.

The proposed method is compared with two well-known TCA techniques, namely, Z-bus and PS methods. Numerical case studies on the 6-bus system and the IEEE 30-bus system show that the proposed method outperforms the other two methods. According to the results, the proposed method is fair and efficient, as it reflects the network topology as well as the order of magnitude and the location of the generators in the grid. Although the PS method intensifies the locational signals, its principle is only based on logical reasoning and can never be proved. It is also shown that the PS principle ignores the counter-flows and, in turn, results in considerable tariff instability. The proposed method, however, smooths the trend of the Z-bus method to reflect the counter-flows, and therefore helps to reduce the cross-subsidies. This property is truly valuable, since higher counter-flows with excessive rewards bring about unfair competitions. Furthermore, based on a comparison on the 6-bus system, it is determined that the results of the cost allocation by the Z-bus method change significantly when different MW-mile pricing schemes are used, whereas the proposed method provides more stable results.

Tariff stability of the proposed cost allocation method is also assessed on the IEEE 30-bus system. The results reveal that the proposed method provides a fairly stable tariffs against the temporal load variations, as well as the generating dispatch strategies. Moreover, based on the results on the 6-bus test system, the proposed method is less sensitive to the calculation reference side of the lines, compared with the Z-bus method. As another advantage, the proposed method works consistently for all network configurations, as it overcomes the singularity problems of the Z-bus as well as PS methods to invert the large-scale sparse matrices. Computational performance on the 2383-bus practical system of Poland indicates that the proposed method is quite fast, so it can well deal with the problem of TCA in large practical power systems.

Open Access This article is distributed under the terms of the Creative Commons Attribution 4.0 International License (http:// creativecommons.org/licenses/by/4.0/), which permits unrestricted use, distribution, and reproduction in any medium, provided you give appropriate credit to the original author(s) and the source, provide a link to the Creative Commons license, and indicate if changes were made. 


\section{Appendix A}

Table A1 Load flow result for IEEE 30-bus test system

\begin{tabular}{|c|c|c|c|c|c|c|}
\hline \multirow[t]{2}{*}{ Bus } & \multicolumn{2}{|l|}{ Voltage } & \multicolumn{2}{|l|}{ Generation } & \multicolumn{2}{|l|}{ Load } \\
\hline & Magnitude (p.u.) & Angle $\left(^{\circ}\right)$ & Real (MW) & Reactive (Mvar) & Real (MW) & Reactive (Mvar) \\
\hline 1 & 0.9824 & 0 & 41.5421 & -5.4364 & 0 & 0 \\
\hline 2 & 0.9787 & -0.7630 & 55.4019 & 1.6748 & 21.7 & 12.7 \\
\hline 3 & 0.9769 & -2.3897 & 0 & 0 & 2.4 & 1.2 \\
\hline 4 & 0.9764 & -2.8386 & 0 & 0 & 7.6 & 1.6 \\
\hline 5 & 0.9713 & -2.4864 & 0 & 0 & 0 & 0 \\
\hline 6 & 0.9723 & -3.2287 & 0 & 0 & 0 & 0 \\
\hline 7 & 0.9623 & -3.4910 & 0 & 0 & 22.8 & 10.9 \\
\hline 8 & 0.9611 & -3.6819 & 0 & 0 & 30 & 30 \\
\hline 9 & 0.9903 & -4.1371 & 0 & 0 & 0 & 0 \\
\hline 10 & 0.9998 & -4.5998 & 0 & 0 & 5.8 & 2 \\
\hline 11 & 0.9903 & -4.1371 & 0 & 0 & 0 & 0 \\
\hline 12 & 1.0174 & -4.4979 & 0 & 0 & 11.2 & 7.5 \\
\hline 13 & 1.0645 & -3.2980 & 16.2002 & 35.9303 & 0 & 0 \\
\hline 14 & 1.0066 & -5.0397 & 0 & 0 & 6.2 & 1.6 \\
\hline 15 & 1.0092 & -4.8140 & 0 & 0 & 8.2 & 2.5 \\
\hline 16 & 1.0028 & -4.8393 & 0 & 0 & 3.5 & 1.8 \\
\hline 17 & 0.9955 & -4.8873 & 0 & 0 & 9 & 5.8 \\
\hline 18 & 0.9933 & -5.4843 & 0 & 0 & 3.2 & 0.9 \\
\hline 19 & 0.9873 & -5.6882 & 0 & 0 & 9.5 & 3.4 \\
\hline 20 & 0.9896 & -5.4719 & 0 & 0 & 2.2 & 0.7 \\
\hline 21 & 1.0093 & -4.6208 & 0 & 0 & 17.5 & 11.2 \\
\hline 22 & 1.0160 & -4.5030 & 22.7403 & 34.1971 & 0 & 0 \\
\hline 23 & 1.0256 & -3.7557 & 16.2670 & 6.9598 & 3.2 & 1.6 \\
\hline 24 & 1.0167 & -3.8852 & 0 & 0 & 8.7 & 6.7 \\
\hline 25 & 1.0438 & -2.0724 & 0 & 0 & 0 & 0 \\
\hline 26 & 1.0267 & -2.4760 & 0 & 0 & 3.5 & 2.3 \\
\hline 27 & 1.0690 & -0.7147 & 39.9090 & 31.7544 & 0 & 0 \\
\hline 28 & 0.9820 & -3.2152 & 0 & 0 & 0 & 0 \\
\hline 29 & 1.0500 & -1.8494 & 0 & 0 & 2.4 & 0.9 \\
\hline 30 & 1.0391 & -2.6429 & 0 & 0 & 10.6 & 1.9 \\
\hline
\end{tabular}

\section{References}

[1] Gao B, Liu X, Wu C et al (2018) Game-theoretic energy management with storage capacity optimization in the smart grids. J Mod Power Syst Clean Energy 6(4):656-667

[2] Wang D, Zhou F, Li J (2019) Cloud-based parallel power flow calculation using resilient distributed datasets and directed acyclic graph. J Mod Power Syst Clean Energy 7(1):65-77

[3] Choi DH, Xie L (2017) Impact of power system network topology errors on real-time locational marginal price. J Mod Power Syst Clean Energy 5(5):797-809

[4] Ma Q, Meng F, Zeng XJ (2018) Optimal dynamic pricing for smart grid having mixed customers with and without smart meters. J Mod Power Syst Clean Energy 6(6):1244-1254
[5] Yang Z, Zhong H, Xia Q et al (2016) A structural transmission cost allocation scheme based on capacity usage identification. IEEE Trans Power Syst 31(4):2876-2884

[6] Achayuthakan C, Dent CJ, Bialek JW et al (2010) Electricity tracing in systems with and without circulating flows: physical insights and mathematical proofs. IEEE Trans Power Syst 25(2):1078-1087

[7] Horsch J, Schafer M, Becker S et al (2018) Flow tracing as a tool set for the analysis of networked large-scale renewable electricity systems. Int J Electr Power Energy Syst 96:390-397

[8] Gan M, Xie K, Li C (2017) Transmission congestion tracing technique and its application to recognize weak parts of bulk power systems. J Mod Power Syst Clean Energy 5(5):725-734

[9] Rubio-Oderiz FJ, Perez-Arriaga IJ (2000) Marginal pricing of transmission services: a comparative analysis of network cost allocation methods. IEEE Trans Power Syst 15(1):448-454 
[10] Ghayeni M, Ghazi R (2011) Transmission network cost allocation with nodal pricing approach based on Ramsey pricing concept. IET Gener Transm Distrib 5(3):384-392

[11] Gil HA, Galiana FD, Da Silva EL (2006) Nodal price control: a mechanism for transmission network cost allocation. IEEE Trans Power Syst 21(1):3-10

[12] Da Silva AML, De Carvalho Costa JG, Lopes Lima LH (2013) A new methodology for cost allocation of transmission systems in interconnected energy markets. IEEE Trans Power Syst 28(2):740-748

[13] Rao MSS, Soman SA (2015) Marginal pricing of transmission services using min-max fairness policy. IEEE Trans Power Syst 30(2):573-584

[14] Telles E, Lima DA, Street A et al (2013) Min-max long run marginal cost to allocate transmission tariffs for transmission users. Electr Power Syst Res 101:25-35

[15] Xiao Y, Wang X, Wang X et al (2016) Transmission cost allocation by power tracing based equivalent bilateral exchanges. CSEE J Power Energy Syst 2(2):1-10

[16] Rao MSS, Soman SA, Chitkara P et al (2010) Min-max fair power flow tracing for transmission system usage cost allocation: a large system perspective. IEEE Trans Power Syst 25(3):1457-1468

[17] Sulaiman MH, Mustafa MW, Shareef H et al (2012) An application of artificial bee colony algorithm with least squares support vector machine for real and reactive power tracing in deregulated power system. Int J Electr Power Energy Syst 37(1):67-77

[18] Bhakar R, Sriram VS, Padhy NP et al (2010) Probabilistic game approaches for network cost allocation. IEEE Trans Power Syst 25(1):51-58

[19] Molina YP, Saavedra OR, Amarís H (2013) Transmission network cost allocation based on circuit theory and the aumannshapley method. IEEE Trans Power Syst 28(4):4568-4577

[20] Zolezzi JM, Rudnick H (2002) Transmission cost allocation by cooperative games and coalition formation. IEEE Trans Power Syst 17(4):1008-1015

[21] Roustaei M, Eslami MK, Seifi H (2014) Transmission cost allocation based on the users' benefits. Int J Electr Power Energy Syst 61:547-552

[22] Shivaie M, Kiani-Moghaddam M, Ansari M (2018) Transmission-service pricing by incorporating load following and correlation factors within a restructured environment. Electr Power Syst Res 163:538-546

[23] Teng JH (2005) Power flow and loss allocation for deregulated transmission systems. Int $\mathrm{J}$ Electr Power Energy Syst 27(4):327-333

[24] Conejo AJ, Contreras J, Lima DA et al (2007) $Z_{\text {bus }}$ transmission network cost allocation. IEEE Trans Power Syst 22(1):342-349

[25] Khalid SN, Shareef H, Mustafa MW et al (2012) Evaluation of real power and loss contributions for deregulated environment. Int J Electr Power Energy Syst 38(1):63-71

[26] Nikoukar J, Haghifam MR, Parastar A (2012) Transmission cost allocation based on the modified Z-bus. Int $\mathrm{J}$ Electr Power Energy Syst 42(1):31-37

[27] Abdelkader SM, Morrow DJ, Conejo AJ (2014) Network usage determination using a transformer analogy. IET Gener Transm Distrib 8(1):81-90
[28] Molina YP, Saavedra OR, Portugal C (2014) Allocation of transmission network cost using modified $Z_{\text {bus }}$ matrix. Int $\mathrm{J}$ Electr Power Energy Syst 63:323-330

[29] De M, Goswami SK (2011) Reactive support allocation using improved Y-bus matrix method. IET Gener Transm Distrib 5(4):448-460

[30] Alturki YA, Lo KL (2010) Real and reactive power loss allocation in pool-based electricity markets. Int $\mathrm{J}$ Electr Power Energy Syst 32(4):262-270

[31] Peng JC, Jiang H, Song YH (2007) A weakly conditioned imputation of an impedance-branch dissipation power. IEEE Trans Power Syst 22(4):2124-2133

[32] Milanovic JV, Yamashita K, Villanueva SM et al (2013) International industry practice on power system load modeling. IEEE Trans Power Syst 28(3):3038-3046

[33] Stamtsis GC, Erlich I (2004) Use of cooperative game theory in power system fixed-cost allocation. IEE Proc Gener Transm Distrib 151(3):401-406

[34] Frontier Economics (2009) International transmission pricing review. https://www.ea.govt.nz/dmsdocument/2539. Accessed 14 February 2018

[35] Rachel T, Igor J, Konrad G et al (2018) Overview of transmission tariffs in Europe: synthesis 2018. https://docstore.entsoe. eu/Documents/MC\%20documents/TTO_Synthesis_2018.pdf. Accessed 1 June 2018

[36] Alexander I, Bamford R (2011) Review of international models of transmission charging arrangements: a report for Ofgem. https://www.ofgem.gov.uk/ofgem-publications/54361/projecttransmitcepareport.pdf. Accessed 15 February 2018

[37] Pai MA (2006) Test system data (Appendix D). In: Computer techniques in power system analysis, 2nd edn. McGraw-Hill, New Delhi, pp 228-231

Saeid POUYAFAR received the B.S. degree in electrical engineering from Khajeh Nasir Toosi University of Technology, Tehran, Iran, in 2007, and the M.S. degree from University of Tabriz, Tabriz, Iran, in 2010, respectively. He is currently pursuing the Ph.D. degree in University of Tabriz. His research interests include power market and security assessment of power systems.

Mehrdad TARAFDAR HAGH is with the Faculty of Electrical and Computer Engineering, University of Tabriz, Tabriz, Iran, since 2000, where he is currently a Professor. He is also with Engineering Faculty of Near East University, North Cyprus, Turkey. He has published more than 300 papers in power system and power-electronic-related topics. His research interests include power system operation, distributed generation, flexible AC transmission systems, and power quality.

Kazem ZARE received the B.Sc. and M.Sc. degrees in electrical engineering from University of Tabriz, Tabriz, Iran, in 2000 and 2003, respectively, and Ph.D. degree from Tarbiat Modares University, Tehran, Iran, in 2009. He is currently an Associate Professor of the Faculty of Electrical and Computer Engineering, University of Tabriz. His research interests include power system economics, distribution networks, microgrid and energy management. 